\title{
Indoor Biomass Fuel Smoke Exposure as a Risk Factor for Chronic Obstructive Pulmonary Disease (COPD) for Women of Rural Bangladesh
}

Rajat Sanker Roy Biswas ${ }^{1 *}$

Sujat Paul ${ }^{2}$

Md Ridwanur Rahaman ${ }^{3}$

Md Abu Sayeed ${ }^{2}$

Mohammed Gofranul Hoque

Md Amir Hossain ${ }^{4}$

Md Mahtab Uddin Hassan ${ }^{5}$

M A Faiz ${ }^{6}$

'Department of Medicine

Chattagram Maa Shishu-O-General Hospital

Chittagong, Bangladesh.

${ }^{2}$ Department of Medicine

Chittagong Medical College

Chittagong, Bangladesh.

${ }^{3}$ Department of Medicine

Shaheed Sarhrawardy Medical College

Dhaka, Bangladesh.

${ }^{4}$ Departmenent Medicine

Chittagong International Medical College (CIMC)

Chittagong, Bangladesh.

${ }^{5}$ Department of Medicine

Anwer Khan Modern Medical College

Chittagong, Bangladesh.

${ }^{6}$ Department of Medicine

Dhaka Medical College

Dhaka, Bangladesh.

\section{${ }^{*}$ Correspondence to:}

\section{Dr. Rajat Sanker Roy Biswas}

Resident Physician

Department of Medicine

Chattagram Maa Shishu-O- General Hospital

Chittagong, Bangladesh.

Mobile : +88 01819808433

Email: rajatbiswas76@yahoo.com

www.banglajol.info/index.php/CMOSHMCJ

\begin{abstract}
Background: Chronic Obstructive Pulmonary Disease (COPD) is of public health importance. Indoor biomass (wood, cowdung etc) smoke exposure from cooking is associated with respiratory conditions and may predispose to COPD. The objective of this study was to evaluate the risk of biomass smoke exposure and COPD Methods: A cross sectional study was conducted at a rural setting of Bangladesh. Rural women over 40 years and exposed to biomass fuel, liquid petroleum gas or natural gas smoke were evaluated using a questionnaire and their lung function was assessed using a portable spirometry. Results: The overall prevalence of COPD in the rural women was $20.4 \%$. It was significantly higher in women using biomass fuel for cooking than in those using natural gas/LPG $(p<0.001)$. Biomass smoke exposure was found significantly associated with $\mathrm{COPD}(\mathrm{OR}=3.385, \mathrm{CI}=1.60-7.13$, $\mathrm{p}<0.05$ ). Lung function was significantly reduced $(\mathrm{p}<0.05)$ among women who were using biomass than those using natural gas/LPG. Conclusion: Biomass fuel smoke exposure is a risk factor for development of COPD.
\end{abstract}

Key words: Biomass; Biomass fuel; Smoke exposure; COPD.

\section{INTRODUCTION}

Chronic Obstructive Pulmonary Disease (COPD) is a preventable and treatable disease with some significant extra pulmonary effects. It is the fourth leading cause of death and affects $>10$ million persons in the United States. In Bangladesh age adjusted death $/ 100,0000$ is 66.4 in $\mathrm{COPD}^{1}$. It is also a disease of increasing public health importance around the world. Estimates suggest that COPD will rise from the sixth to the third most common cause of death worldwide by $2020^{2}$.

Risk factors of COPD include both host factors and environmental exposure. The disease occurs due to interaction between two types of factors. Among the various environmental factors, tobacco smoke, exposure to biomass fuel smoke and to occupational dust and chemicals, indoor/outdoor air pollution, infection especially childhood respiratory infection and low socioeconomic status are important ${ }^{2}$.

Biomass is a group of biologic materials like living organisms both animals and vegetables, which after combustion, produces huge smoke. ${ }^{3}$ Some of these materials like wood, bamboo, cow dung, shell and coir of coconut, saw dust, agricultural crop residues are used as fuel for cooking in developing countries like Bangladesh and for home heating in other countries ${ }^{4}$. Close to $50 \%$ of world population in China, India, Bangladesh and sub-Saharan Africa use biomass fuels ${ }^{3}$.

Use and exposure to biomass fuel smoke is responsible for different health hazards like COPD, tuberculosis, bronchial carcinoma. Different studies in many countries established that COPD is a leading respiratory problem in nonsmokers who are using the biomass fuel ${ }^{5}$. But in Bangladesh this field is yet to be explored largely. There is a need to develop evidence based methods which can assess the health risks of the rural women and develop safe cooking procedures or alternate fuels for cooking. 


\section{MATERIALS AND METHODS}

This cross sectional observational study was involved the five rural (Villages) areas of Chittagong, Bangladesh during a one year study period from March 2010 to February 2011. There are total 14 Upazillas in Chittagong, Bangladesh where people use biomass fuel for cooking. Among these, people of eight upazillas also use LPG/Natural gas along with biomass. The areas are virtually indistinguishable from each other in terms of socioeconomic status, economy, diet, and access to health care. They are matched on these key characteristics and thus minimized the potential for confounding factors. In a pre survey visit it was found that cooking is mainly done indoors with an open fire traditional cooking stove in a small adobe kitchen with wood or grass made roof with or without any ventilation. During cooking the biomass fuels are placed in a hole that is carved out of the middle part of the stove below the area for the pots and pans. The kitchens are filled with heavy smoke during biomass fuel combustion. Of those 14 Upazillas, 5 Upa zillas were randomly selected first by lottery methods. Then from those 5 upazillas, one village from each was selected again randomly then 3-4 paras (Small community clusters) were selected from each village. Starting from the beginning of a road of a selected para, every alternate house was visited and women above 40 as per National ID Card and residing there and fulfilling inclusion criteria were included in the study after informed consent. At least 25 women from each paras were interviewed using a case record form with a pre tested questionnaire (Bengali version). The questionnaire was validated by a small pilot study. A total of final 250 women were included in the data analysis after exclusion (Figure 1). Classically COPD is mainly found after 40 years, so an age bar of 40 years was taken as an inclusion criteria.

After getting consent all selected women were asked to complete a structured questionnaire to obtain sociodemographic data related to personal information, cooking practice, information related to respiration and allergy, cough, sputum and respiratory distress. Clinical examination was done and assessment of pulmonary function was done by spirometer (CMS-SP 10).Post bronchodilator reversibility test was done on those who had abnormal findings on initial spirometry without bronchodilator. After pre- bronchodilator spirometry, four puffs of salbutamol (400 mcgm) was given by a metered dose inhaler with a spacer device. After 15 minutes, a post bronchodilator spirometry result was taken. Women who had FEV1/FVC $<0.70$ and was found to be irreversible in postbrochodilator spirometry were selected as having COPD. Patients who documented history of respiratory disease, were excluded from the study. Those having suspicious history of bronchial asthma were selected for the study initially. But after getting reversible post bronchodialator spirometry they were excluded. The questionnaire introduced in the current study was revised from a study on "Burden of Chronic Obstructive Lung DiseaseBangladesh (BOLD-BD)" done by Hasan et al. $2007^{6}$. Exposure to biomass smoke was defined as using biological material (Mainly wood, charcoal, grass and crop residues or dung) for cooking or heating for $10 \mathrm{yr}$. Poor ventilation referred to places which did not have any opening in the kitchen. Subjects with a parent or sibling diagnosed with chronic bronchitis, emphysema, asthma or COPD were deemed as having a family history of respiratory diseases. In the study a portable spirometer was used and procedure of spirometry was done as recommended by the American Thoracic Society. Selected subjects had bronchodilation tests within 15-20 min of being given a dose of $200 \mu \mathrm{g}$ of salbutamol (Ventolin, GlaxoSmithKline, Uxbridge, UK) inhaled through a $500-\mathrm{mL}$ spacer.

Data was analysed with Statistical Package for Social Science (SPSS) version 18.0 (Chicago, Illinois, USA).Association of lung function among different fuel users were analyzed by chi square $\left(\chi^{2}\right)$ test. Mean with confidence interval of quantitative variables were analyzed by ANOVA and presented as error bar. Risk of COPD with exposure to biomass fuel and others were calculated by multiple logistic regression technique and calculation of odds ratio.

\section{RESULTS}

Figure 1: Study design.

Selection of study area (Five Upa Zillas of Chittagong Bangladesh) Selection of village woman from the selected house $\downarrow$

Consent was taken after explanation of the study procedure $\downarrow$

Initial screening by history and clinical examination $(\mathrm{n}=276)$

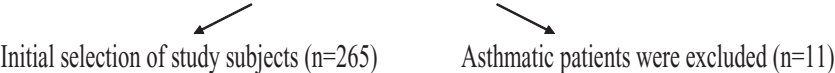

$$
\downarrow
$$

Subjects were prepared for spirometry

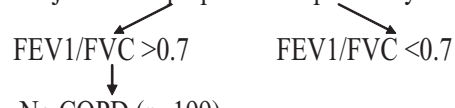

No COPD (n=199)

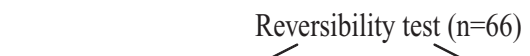

$$
\downarrow
$$

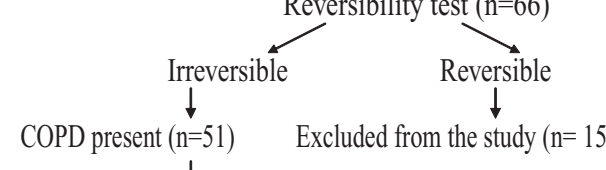

Data sheet was filled up and questionnaire introduced

$$
\text { Data analysis }(\mathrm{n}=250)
$$

Among the 250 females, $150(60 \%)$ were biomass fuel users and Natural gas/LPG users were 100 (40\%). COPD was found in $41(16.4 \%)$ biomass users and $10(4 \%)$ in later. The frequency of COPD was $20.4 \%$ with a higher number in women who were using biomass then who were using natural gas/LPG $(\mathrm{p}<0.001)$. Regarding risk analysis, biomass fuel was found significantly associated with COPD $(\mathrm{OR}=3.385$, $\mathrm{CI}=1.606-7.135, \mathrm{p}<0.05)$. Multinomial logistic regression analysis showed respiratory distress in family members (OR$0.63)$ nature of kitchen (1.20) seasonal variation in cooking (OR-1.24), cough in childhood (OR-0.33) tobacco chewing habit (OR-12.49) type of stove (OR-0.19) history of cough (OR-0.13) and life time smoking history (OR-0.37) risk factors. Lung function also was significantly reduced $(\mathrm{p}<0.05)$ among women using biomass. 
Table 1 : Distribution of the subjects according to age groups $(\mathrm{n}=250)$.

\begin{tabular}{|c|c|c|c|c|c|}
\hline \multirow{2}{*}{$\begin{array}{l}\text { Type of } \\
\text { Subject }\end{array}$} & \multicolumn{4}{|c|}{ Age Group* } & \multirow[b]{2}{*}{ Total } \\
\hline & $40-49(n=158)$ & $50-59(n=50)$ & $60-69(n=34)$ & $>70(\mathrm{n}=8)$ & \\
\hline COPD & $5(9.8 \%)$ & $15(29.4 \%)$ & $26(51.0 \%)$ & $5(9.8 \%)$ & $51(100.0 \%)$ \\
\hline No COPD & $153(76.9 \%)$ & $35(17.6 \%)$ & $8(4.0 \%)$ & $3(1.5 \%)$ & $199(100.0 \%)$ \\
\hline
\end{tabular}

* Age was expressed in years

Table 2: Fuel use $(\mathrm{n}=250)$.

\begin{tabular}{|c|c|c|c|}
\hline $\begin{array}{l}\text { Type of } \\
\text { Subject }\end{array}$ & Biomass & $\begin{array}{c}\text { Fuel Type } \\
\text { Natural gas/LPG }\end{array}$ & Total \\
\hline COPD & $41(80.4 \%) 1$ & $0(19.6 \%)$ & $51(100.0 \%)$ \\
\hline No COPD & $109(54.8 \%)$ & $90(45.2 \%)$ & $199(100.0 \%)$ \\
\hline
\end{tabular}

Chi-Square Tests, $\chi^{2}=11.1, \mathrm{df}=1$ and $\mathrm{p}=0.001, \mathrm{OR}=3.385, \mathrm{CI}=1.606-7.135$

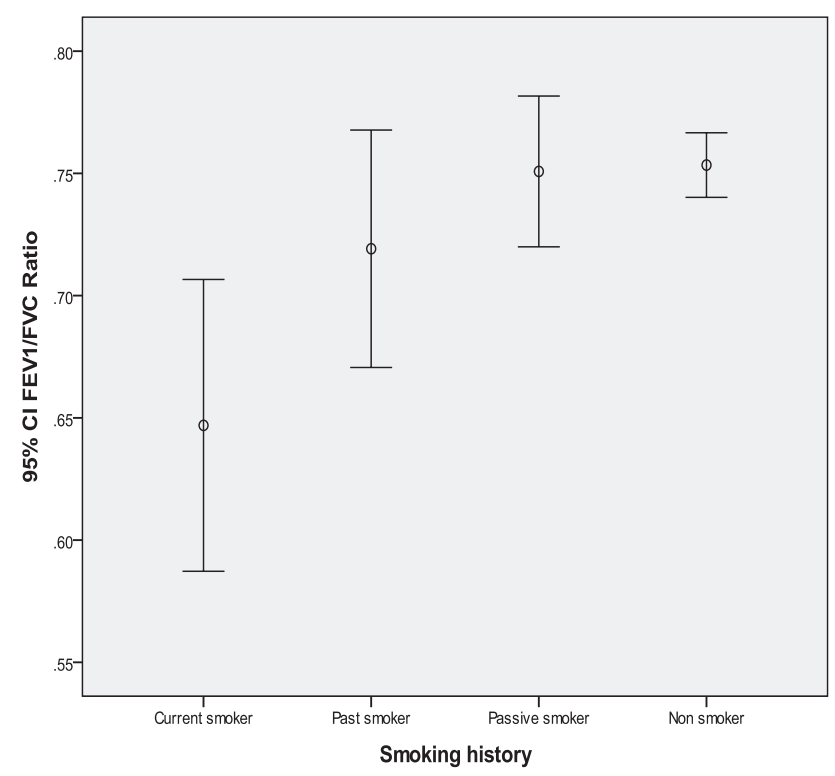

Figure 2: Relation of FEV1/FVC with smoking $(\mathrm{n}=150)$.

Table 3 : Relation of COPD with duration of cooking $(n=250)$.

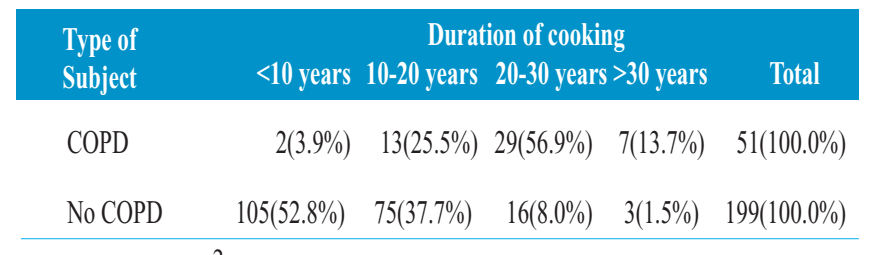

Chi-Square Tests, $\chi^{2}=93.253, \mathrm{DF}=3, \mathrm{p}=0.001$
Table 4 : Association of risk behavior with COPD.

\begin{tabular}{|c|c|c|c|c|}
\hline $\begin{array}{l}\text { Risk behaviors } \\
(\mathrm{n} / \%)\end{array}$ & COPD & OR & CI & p -value \\
\hline $\begin{array}{l}\text { Nature of kitchen } \\
\text { Open } \\
\text { Closed }\end{array}$ & $\begin{array}{l}13(14.3 \%) \\
38(23.9 \%)\end{array}$ & 1.206 & $0.471-3.092$ & 0.696 \\
\hline $\begin{array}{l}\text { Seasonal variation } \\
\text { in cooking } \\
\text { Seasonal } \\
\text { Always }\end{array}$ & $\begin{array}{l}9(12.3 \%) \\
42(23.7 \%)\end{array}$ & 1.245 & $0.448-3.465$ & 0.675 \\
\hline $\begin{array}{l}\text { Tobacco chewing habit } \\
\text { Present } \\
\text { Absent }\end{array}$ & $\begin{array}{r}40(16 \%) \\
11(4.4 \%)\end{array}$ & 12.941 & $3.388-49.44$ & 0.001 \\
\hline $\begin{array}{l}\text { Type of stove } \\
\text { Outdoor } \\
\text { Indoor }\end{array}$ & $\begin{array}{l}3(1.2 \%) \\
48(19.2 \%)\end{array}$ & 0.191 & $0.075-0.485$ & 0.001 \\
\hline $\begin{array}{l}\text { Life time smoking history } \\
\text { Present } \\
\text { Absent }\end{array}$ & $\begin{array}{l}16(6.4 \%) \\
35(14.01 \%)\end{array}$ & 0.376 & $0.138-1.026$ & 0.056 \\
\hline $\begin{array}{r}\text { Fuel type } \\
\text { Biomass } \\
\text { NG/LPG }\end{array}$ & $\begin{array}{l}41(16.4 \%) \\
10(4 \%)\end{array}$ & 0.316 & $0.119-0.833$ & 0.02 \\
\hline
\end{tabular}

$\mathrm{OR}=$ Odds ratio, $\mathrm{CI}=$ Confidence interval

\section{DISCUSSION}

Biomass smoke contain a large number of pollutants and it is a known health hazard ${ }^{7}$. Exposure to indoor air pollution from the combustion of biomass fuels causes several diseases in developing countries, including Acute Respiratory Infections (ARI) and Otitis media (Middle Ear Infection) Chronic Obstructive Pulmonary Disease (COPD) Lung cancer, Asthma, Cancer of the nasopharynx and larynx, Tuberculosis, Perinatal conditions and Low birth weight, and diseases of the eye such as Cataract and blindness ${ }^{7}$.

Biomass fuel use for cooking by rural women in Bangladesh has an association with COPD. Increased prevalence of COPD was found in women who use biomass $(16.4 \%)$ then women who use natural gas or LPG (4\%). Overall prevalence of COPD in the areas studied among women above 40 was $20.4 \%$. Regarding risk analysis biomass fuel was found significantly associated with COPD $(\mathrm{OR}=3.385, \mathrm{CI}=1.606-7.135, \mathrm{p}<0.05)$. The effects of biomass smoke influenced the development of COPD in different ways. Similar studies done in Turkey found that the prevalence of COPD in group exposed to biomass fuel was higher than that in the LPG group $(28.5 \%$ vs. $13.6 \%$ crude ODs ratio $=2.5, \mathrm{CI}=1.5-4.0, \mathrm{p}=0.001)$. The fraction of COPD attributed to exposure to biomass smoke after adjusting for possible confounding factors was $23.1 \%$ (95\% confidence interval: $13.4-33.2)^{5}$. In a study done in China also found that the use of biomass is a risk factor of $\mathrm{COPD}^{8}$. The nonsmoking women who are using biomass have higher prevalence of COPD than those who are using LPG (7.2\% vs 2.5\%). Logistic regression analysis also showed statistically significant result among the biomass uses and LPG users $(\mathrm{OR}=3.11, \mathrm{CI}=1.63$ 5.94, $\mathrm{p}=<0.001)$. 
In the current study, most of the female $(63.2 \%)$ were in the age group of 40- 49. But sufferers of COPD were found to have higher age groups ( $>60$ years, $51 \%)$. It was also found that an increase in age was related with lowering of the lung function $(\mathrm{p}<0.05)$. It may be due to direct effects of different risk factors along with decreased lung compliances. A prevalence study done in Bangladesh found also that increasing age in rural women was an important contributing factor to $\mathrm{COPD}^{6}$.

Life time smoking history was common among the subjects with $\operatorname{COPD}(31.4 \%)$. This might be an important confounding factor in relation with influence to biomass fuel with COPD. FEV1/FVC ratio was found significantly reduced among the current and past smokers than nonsmokers $(p<0.05)$ as expected.

Present study highlighted the association of COPD with biomass fuel smoke exposure but the study women had some confounding risk factors. Multinomial logistic regression analysis showed respiratory distress in family members (OR$0.633)$ nature of kitchen (1.206) seasonal variation in cooking (OR-1.245) cough in childhood (OR-0.336) tobacco chewing habit (OR-12.491) type of stove (OR-0.191) history of cough (OR-0.130) and life time smoking history (OR-0.376) might had some influence on the development of COPD to rural women.
While rural communities in developing countries rely mainly or exclusively on biomass fuels such as wood, agricultural crop residues, animal dung, families in better developed areas increasingly use LPG or natural gas as a major source of domestic energy. Evidence from limited number of studies suggests that the smoke from biomass fuel combustion may be associated with functional and structural changes in the respiratory system but confounding by other factors associated with traditional lifestyle cannot be ruled out.

\section{CONCLUSION}

Data from rural areas of Chittagong, Bangladesh support exposure to indoor biomass fuel smoke is associated with COPD among the rural women. Smoking, low educational level, indoor air pollution by biomass during cooking, tobacco chewing habit also play as a contributing factors for development of COPD in rural women. So efforts should be made to give the message to village women to adopt the necessary changes in attitudes and behavior of cooking practice.

\section{DISCLOSURE}

All the authors declared no competing interest.

\section{REFERENCES}

1. Mannino MD, Buist AS. Global burden of COPD: Risk factors, prevalence, and future trends. Lancet. 2007;370: 765-773.

2. Pauwels RA, Buist AS, Peter Calverley PM, Jenkins CR, Hurd SS. GOLD Scientific Committee. Global strategy for the diagnosis, management and prevention of chronic obstructive pulmonary disease. NHLBI/WHO global initiative for chronic obstructive lung disease (GOLD) workshop summary. Am J Respir Crit Care Med. 2001;163:1256-1276.

3. Duque TC, Maldonado D, Padilla, Ezzati M Viegi G. Biomass fuels and respiratory disease, The Proceedings of American thoracic society. 2008; 5: 557-590

4. Raherison C, Girodet PO. Epidemiology of COPD. Eur Respir Rev. 2009;18(114):213-221.

5. Aydanur E, Mehmet E, Ercan K, Ahmet A, Mesut A, Turkan K et al. Obstructive airway disease in women exposed to biomass smoke. Environmental Research. 2005; 99: 93-99.

6. Hasan MR, Rahman MM, Hossain MA, Mahmud AM, Ahmed MM, Bennor KS et al. Burden of obstructive lung disease in Bangladesh (BOLD-BD-2007). Report of national COPD study. 2010.

7. Ezzati M, Kammen DM. Quantifying the effects of exposure to indoor air pollution from biomass combustion on acute respiratory infections in developing countries. Environ Health Perspect. 2001; 109: 481-488.

8. Liu S, Zhou Y, Wang X, Wang D, Lu J, Zheng J et al. Biomass fuels are the probable risk factor for chronic obstruct pulmonary disease in rural South China. Thorax. 2007;62:889-897. 